EPJ Web of Conferences 33, 04002 (2012)

DOI: $10.1051 /$ epjconf/20123304002

(C) Owned by the authors, published by EDP Sciences, 2012

\title{
Smart thermal networks for smart cities - Introduction of concepts and measures
}

\author{
R.R. Schmidt ${ }^{1, \mathrm{a}}$, O. Pol $^{1}$, D. Basciotti ${ }^{1}$, J. Page $^{1}$, \\ ${ }^{1}$ AIT Austrian Institute of Technology, Energy Department, Giefinggasse 2, 11210 Vienna, Austria
}

\begin{abstract}
In order to contribute to high living standards, climate mitigation and energy supply security, future urban energy systems require a holistic approach. In particular an intelligent integration of thermal networks is necessary. This paper will briefly present the "smart city" concept and introduce an associated definition for smart thermal networks defined on three levels: 1 . the interaction with urban planning processes and the interface to the overall urban energy system, 2. the adaptation of the temperature level and 3. supply and demand-side management strategies.
\end{abstract}

\section{Introduction}

To achieve climate mitigation and energy supply security targets, questions related to heat generation, storage and distribution have to be addressed, since almost half of the final energy use in Europe is related to heating services [1]. Thus, thermal networks will become an integral element for a sustainable energy supply of the smart cities of the future. Based on the adaptation of the definition of smart electrical grids and literature review a concept for smart thermal networks is proposed and explained.

\section{1 concepts and topics for smart cities}

The "smart city" approach considers urban systems in all their complexity (holistic approach). In particular interactions between energy and mobility, water, waste, the quality of life of its citizens and socio-economic conditions within the city are addressed explicitly from an energy point of view (demand, supply, distribution, storage). This involves considering the following topics which should not be handled individually, but addressed in a general and integrated planning and implementation framework at city scale:

1. Energy Efficiency: The challenge of energy demand in existing buildings should be addressed by a significant increase of refurbishment rates. For new buildings, ambitious energy standards should be applied. Also other infrastructure components have to operate efficiently, e.g. e.g. mobility, water, waste and communications.

\footnotetext{
a e-mail : Ralf-Roman.Schmidt@ait.ac.at
}

This is an Open Access article distributed under the terms of the Creative Commons Attribution License 2.0, which permits unrestricted use, distribution, and reproduction in any medium, provided the original work is properly cited. 
2. Smart energy networks: Smart electrical and thermal grids are used to collect and distribute energy within a city. Active buildings will play an active role in an intelligent energy networks due to local energy generation and the opportunities provided by demand-side-management activities.

3. Local integration of renewable (and low carbon) energy technologies: Available renewable energy potentials like solar, geothermal, wind and industrial waste heat should be optimally integrated into urban energy system.

4. Meta-regional integration of energy generation from renewable sources: The smart city should be capable of adapting its energy demand profile to the Europe-wide energy generation from renewable sources, e.g. load shifting could be used to match energy end-use with the fluctuating energy imports from wind or solar energy that are expected to increase in the future.

\section{2 methods for smart cities}

The smart cities concept relies on the integration of: 1. processes (e.g. policy, decision making, urban and infrastructure planning processes, financing and stakeholder processes), 2. concepts (e.g. integrated planning and design approaches, energy efficiency measures; decentralised and centralised energy production strategies for heat, cold, electricity and fuels; mobility, waste and water strategies) and 3. technologies (e.g. trigeneration technologies, renewable energy technologies, storage technologies, technologies for cascade use of resources, smart electrical and thermal network components, mobility technologies, information and communication technologies). In particular, the use of Information and Communication Technologies aims at guaranteeing:

-an optimal design and operation of the urban energy system

- the communication between technologies

-monitoring the performance of the smart cities

-the communication with end-users.

\section{Smart district heating and cooling networks}

The main challenges and at the same time opportunities for thermal networks within a smart city will be: 1. Decreasing heat demand of residential buildings due to high building energy standards and increasing retrofitting rates on the one hand, and increasing comfort needs (including cooling) on the other hand. 2. Increasing fossil fuels costs, together with increasing fraction of fluctuating renewable resources fed into the networks. 3. The trend for liberalised heat markets. To face these challenges, thermal networks have to become "smart" as well, which includes the three main elements shown in Fig. 1.

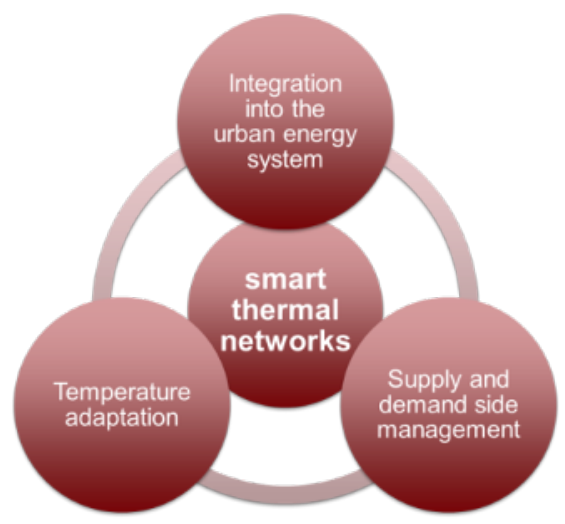

Fig. 1 Different levels of smart thermal networks 


\subsection{Integration into the urban energy system}

The integration of district heating and cooling networks into the overall urban energy system can be considered from a topological point of view and from a system point of view (holistic energy system consideration). The first is related to the way urban form impacts networks availability and topology. The latter is related to the coupling between district heating networks and energy conversion, distribution and storage technologies.

\subsubsection{Topological point of view}

Thermal networks are an integral part of the urban energy system. Their extension and development has to be coordinated within the urban planning framework. Parameters like urban morphology (density, height and typology of buildings), end-use mix, building energy performance characteristics and socio-economic factors (education, income, gender) directly and indirectly impact energy demand, e.g. [2]. These factors finally determine whether and where district heating or cooling networks are feasible and in which configurations they should be designed. Primarily urban planning parameters influence the heating and cooling demand density and therefore the network feasibility. In this context there might be some conflicting objectives between network feasibility and urban planning choices: densely built urban settlements are favourable for district heating infrastructure whereas sparse neighbourhoods are not always adapted, even if the feasibility of district heating networks in sparse areas has already been demonstrated for given conditions (for instance in [3]).

Beyond this, urban form parameters might influence the network extension (city-wide networks vs. micro networks) or the necessity to implement a heat transport infrastructure:

\section{City-wide network vs. micro networks}

To increase the potential for using renewable heat resources in a city, it is necessary to use and distribute efficiently heat from solar systems, ambient and geothermal sources as well as industrial processes. This includes the setup of thermal micro networks aside traditional district heating networks in order to connect nearby buildings, local resources and if necessary storage facilities to reach a local optimum. Some examples for established micro networks can be found in e.g. [4], [5].

\section{Transport networks}

Large amounts of industrial waste heat are usually available outside dense populated areas and might require heat transport infrastructure towards cities. The following two examples illustrate the heat transport over large distances:

- Since the 1980ies, a district heating system with a total length of $80 \mathrm{~km}$ is connecting the cities of Kolding, Fredericia, Middelfart and Vejle in Denmark. In a joint project of 8 district heating companies, about $1400 \mathrm{GWh} / \mathrm{a}$ heat energy from waste incineration, refinery waste heat and CHP processes is distributed. A network extension is currently planned [6].

- In 2009, a district heating line from the power plant Dürnrohr (Waste incineration, CHP, biomass) with a total length of $31 \mathrm{~km}$ and a diameter between 0.4 and $0.45 \mathrm{~m}$ was constructed. Approximately $200 \mathrm{GWh} / \mathrm{a}$ heat energy is delivered to the city of St. Pölten (52.000 inhabitants), covering roughly $2 / 3$ of its heat demand [7].

\subsubsection{System point of view}

The system point of view consists in considering how thermal networks interact with other parts of the urban energy system, e.g. the electricity network via CHP (combined heat and power) processes or heat pumps. This consists for instance in assessing how a variation of district heating demand impacts the electricity generation in CHP (for instance [8]) or in finding the optimum solution for generating heat, cooling energy, and electricity to cover the demand of a given city or district. Existing district heating networks should be used for the distribution of heat, but extension of 
networks (especially in built up areas) can be costly and intrusive. Since heat pumps coupled to e.g. CCGT CHP can offer a higher overall system efficiency, they can be used as a ,virtual“ extension of an existing district heating/cooling network by decentralised production of heat and distribution via micro-grids [9], see Fig. 2. Similar options are also possible in combination with district cooling networks considering compression and absorption chillers.

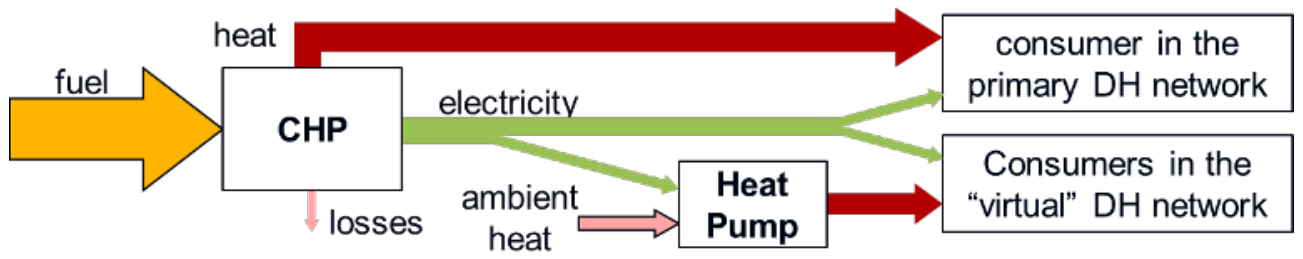

Fig. 2 interface to electricity system: coupling between CHP and heat pumps

Another example [10] shows a similar configuration but includes seasonal heat storage for the integration of fluctuating renewable energy resources. Depending on the market price for electricity, either the heat pump (low price) or the CHP plant (high price) operates. The generated heat energy is then either delivered to the consumers (winter) or stored in the heat storage (summer). Above that, a heat only boiler is used for back up and peak loads and solar thermal collectors are used for additional charging the seasonal storage.

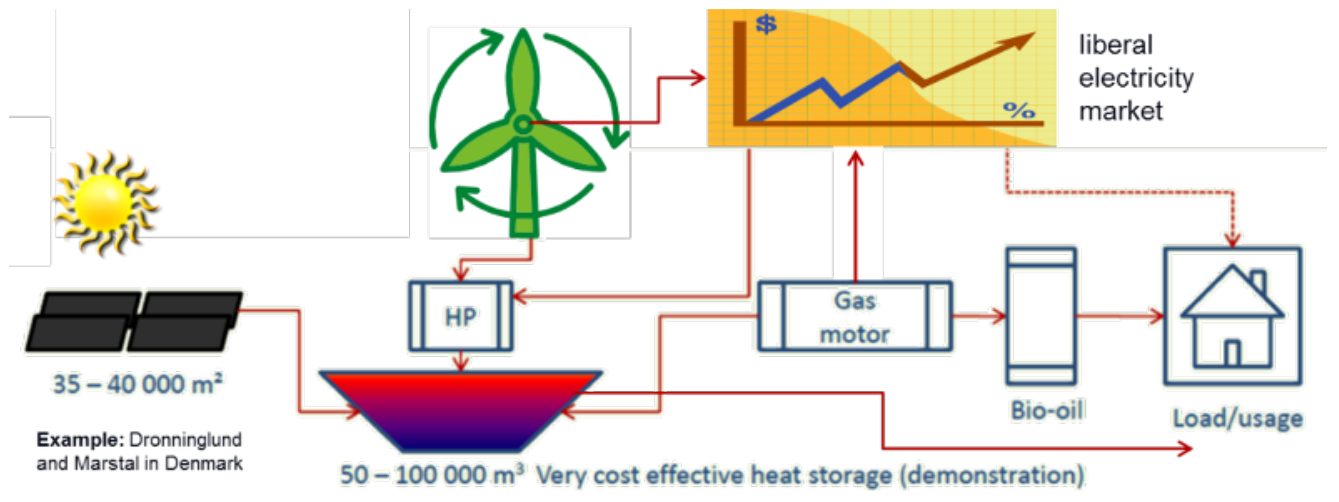

Fig. 3 interface to electricity system: integration of renewables [10] (modified)

\subsection{Temperature adaptation}

Space heating in traditional residential buildings has generally been ensured by radiation heat transfer from radiators at about $70^{\circ} \mathrm{C}$. District heating networks have traditionally been designed for supply temperatures ranging from $90^{\circ} \mathrm{C}$ to $140^{\circ} \mathrm{C}$ (pressurised or vapour networks). As a result, the distribution losses in district heating systems are usually in the range of 10-30\%. Current building energy performance improvement trends contribute to a decreasing district heat demand ${ }^{\mathrm{b}}$, which leads to an increase of the relative distribution losses and a decrease of the cost effectiveness of district heating networks ${ }^{c}$.

It is the best way to counteract this trend consists in reducing heat supply temperatures to e.g. 30$50^{\circ} \mathrm{C}$ in order to lower distribution heat losses. This temperature level is sufficient to gain comfortable room temperatures in buildings with suitable heating systems (e.g. floor heating, concrete core activation) e.g. [11], [12], [13]. Additionally, low supply temperatures will increase the potential of renewable energy resources like solar thermal energy and low temperature waste heat

\footnotetext{
${ }^{\mathrm{b}}$ in some cases also due to deurbanization, e.g. some cities in the new federal states of Germany

${ }^{\mathrm{c}}$ This is valid also for sparsely populated areas [3]
} 
(e.g. heat rejection from cooling towers). Also heat pumps could operate at a high efficiency in low temperature networks for temperature modulation if necessary. Moreover, low temperatures might enable using flexible plastic piping with the possibility of lower investment costs (due to cost effective installation). Another possible option for buildings with low temperature heating systems consists in connecting to the return line of existing networks, e.g.: [14], [15]. This would have the advantage of increasing the overall system efficiency by increasing the rate of fuel utilisation.

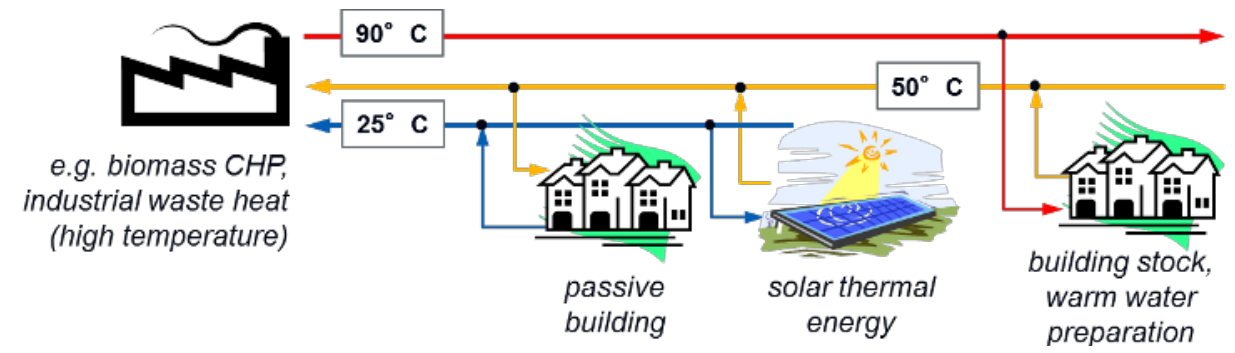

Fig. 4 Example for the integration of buildings with low temperature heating systems (e.g. passive buildings) and renewable energy like solar thermal collectors in the return line of existing networks

One major issue in low temperature networks is the production of domestic hot water (DHW). Depending on national regulations, when storing DHW a minimum temperature level has to be kept to avoid legionella propagation ${ }^{\mathrm{d}}$. In general, following approaches ${ }^{\mathrm{e}}$ are available for producing DHW in low temperature networks:

1. Supply temperatures above $65^{\circ} \mathrm{C}$. This option is a trade-off to traditional systems, having slightly lower distribution losses and increased potential for renewable energies.

2. Direct DHW preparation without storage facilities at a minimum supply temperature of 45 to $50^{\circ} \mathrm{C}$. This solution will result in high peak loads as the direct preparation of DHW requires high heating power. One possibility would consist in installing storage tanks on the network side (centralised or distributed) to handle these peak loads, e.g. [16] (see also section 2.3).

3. Additional heating could be applied to the DHW storage when temperature is below $65^{\circ} \mathrm{C}$. (e.g. via heat pumps, electric heaters, solar energy...). This could be done either

a. directly at the consumer substations or

b.in a central heating station. Here, the heat carrier with the high temperature could be distributed to the consumers in a separate supply line in a three-pipe system.

An ecological and economical optimum solution for low-temperature networks and the actual supply temperature depends on many different parameters like consumer structure and demand characteristics, available (renewable) energy resources, possible storage capacities (long- and short term) and network topology for new or existing networks. As a result, these approaches have to be assessed for each situation independently.

\subsection{Supply and demand side management}

Significant peak loads (especially in the morning and evening) are challenging for the operation of district heating systems, see Fig. 5. In most cases, peak load generation units have to be kept on stand-by to cover the peak demand. For economic reasons, these are usually boilers (without combined power generation) based on fossil combustibles (gas, oil). Due to high specific heat costs through low utilization ratio and expensive combustibles, operating these peak demand boilers

\footnotetext{
${ }^{\mathrm{d}}$ e.g. Austrian standard ÖNORM B 5019: in public buildings, $60^{\circ} \mathrm{C}$ has to be exceeded permanently when storing DHW

${ }^{\mathrm{e}}$ Not considering chemical disinfection
} 
compromises the economic and environmental performance (high specific $\mathrm{CO}_{2}$ emissions) of district heating systems.

Within a nationally funded research project (SmartHeatNetworks ${ }^{f}$ ), various supply and demand-side measures to reduce daytime-related peak loads were defined and assessed for the chosen model of a district heating system of a medium size village. Some of them are presented below briefly.
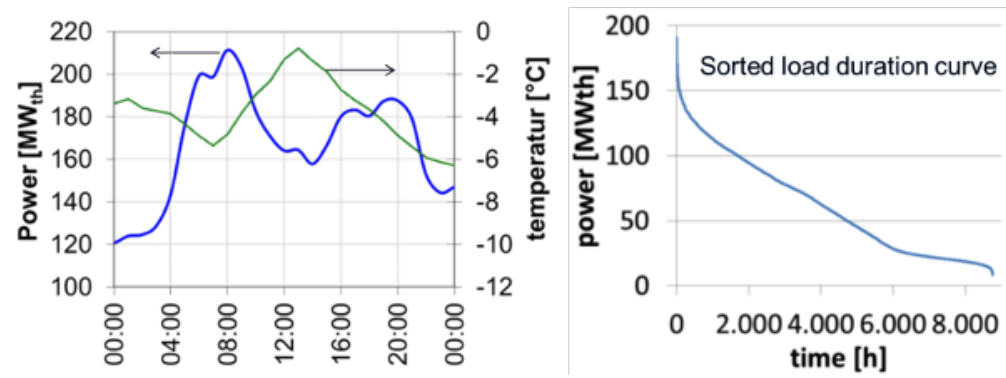

Fig. 5 Peak loads in thermal networks (example for the district heating network of the city of Salzburg (AT))

\subsubsection{Load shifting in thermal networks}

Load shifting could be done either to minimize the peak loads in a network by shifting the loads to off peak times (e.g. [17]) or to adapt the energy demand to fluctuating energy resources like solar thermal energy by shifting the loads to times with surplus energy. In district heating networks, the most relevant load is the heating energy of the buildings need to heat up e.g. from a night setpoint to a day setpoint ${ }^{\mathrm{g}}$. However, load shifting in thermal networks is rarely implemented, mainly because the absence of suitable smart meters and the lack of motivation as long as heat in district heating networks is usually produced by combined heat and power plants (CHP plants) and it is not applicable to energy markets with time variable tariffs and fossil fuels for peak load coverage are relatively cheap [18].

\subsubsection{Utilizing the capacity of the district heating network as a storage}

The water volume contained in the DH network piping can be assimilated to large storage units and can be used for peak reduction purposes (e.g. [19], [20], [21]). Considering the limited storage capacity, possible applications are restricted to hourly peak shaving. Generally, control systems in DH networks are made by two independent loops, the control variable being the network supply temperature in one loop and the pressure drop between supply and return line at the last substation in the other loop. In [22] an advanced control technique for storing heat in the network is proposed and assessed by simultaneously varying supply temperature and pressure drop (i.e. mass flow). The effect of the optimised control strategy in a typical winter day is a peak load reduction of about $15 \%$. The related distribution losses increase about $0.3 \%$.

\section{Conclusion}

Smart thermal networks will play an important role in the future of urban energy systems. Their properties will consist of the following three elements:

\footnotetext{
${ }^{\mathrm{f}}$ This project is supported with funds from the Climate and Energy Fund and Implemented in line with the "New Energies 2020" programme (project nr. 825549). This project is part of the "Smart Grids Modellregion Salzburg", http://www.smartgridssalzburg.at/

${ }^{g}$ Other conceivable loads could be storage for domestic hot water, household appliances with connection to $\mathrm{DH}$, swimming pools ...
} 
1. A sound integration of thermal networks into the urban energy system, by considering urban planning framework, the interfaces to other energy networks and the many possibilities of conversion (e.g. heat pumps) and coupling (e.g. cogeneration). In addition to traditional centralised structures, the installation of distributed micro-networks and connections to energy sources in surrounding regions will contribute to achieve an overall optimum.

2. The key function of thermal networks, the distribution of heating and cooling energy from (distributed) sources, will be enhanced by adapting the temperature level to the needs of the consumers (e.g. $30^{\circ} \mathrm{C}$ could be sufficient for space heating), thus reducing distribution losses and increasing the potential of renewable energy resources like solar thermal energy and industrial waste heat.

3. Smart thermal networks will have additional metering and controlling equipment to enable supply- and demand-side load management. The utilisation of the network capacity itself together with storage units provide additional potential for adapting to fluctuating energy generation from renewable sources and reducing peak loads.

\section{References}

[1] European Technology Platform on Renewable Heating and Cooling: 2020 - 2030 - 2050, Common Vision for the Renewable Heating \& Cooling sector in Europe, Luxembourg: Publications Office of the European Union, 2011

[2] Pol, O., Robinson, D., Impact of urban morphology on building energy needs: a review on knowledge gained from modeling and monitoring activities, CISBAT 2011, Lausanne

[3] Zinko H. et al., District heating distribution in areas with low heat demand density, Report of the IEA Implementing agreement on District Heating and Cooling, including the integration of CHP, Annex VIII, 2008:8DHC-08-03, Editor Heimo Zinko, 2008

[4] Pauschinger, T.: Solarthermie in der Nah- und Fernwärmeversorgung - Aktuelle Entwicklungen in Deutschland und Europa, Berliner Energietage 20.5.2011

[5] Schubert, M.: Solare Nah- und Fernwärmeeinspeisung in Österreich, C.A.R.M.E.N. Symposium Solarunterstützte Nahwärme, 12.07.2011, Straubing

[6] Bjørn, H; Kristensen, K.; Hammer, F.: District heating based on surplus energy, international magazine on district heating and cooling, No. 2 2009, http://www.e-pages.dk/dbdh/8/6

[7] Oberhammer, A.: Die längste Fernwärmeleitung Österreichs, Bericht über die Planung, den Bau und die Qualitätssicherung, Fernwärmetage 2010, 17. -18. März 2010

[8] Gustavsson, L., et al.: Primary energy implications of end-use energy efficiency measures in district heated buildings, Energy and buildings 43 (2011), 38 - 48

[9] Mancarella, P.: Distributed Multi-Generation Systems: Energy Models and Analyses, Nova Science Pub Inc (August 2008)

[10] Nielsen, J.E.: The Contribution of Renewable Heating and Cooling technologies to the "Smart Cities initiatives” Smart District Heating Workshop February 9th 2011, Brussels

[11] Introduction to the Concept of Exergy - for a Better Understanding of Low-TemperatureHeating and High-Temperature-Cooling Systems, Submitted to IEA ANNEX37 "Low Exergy Systems for Heating and Cooling of Buildings", April 25, 2002 
[12] Heating and Cooling with Focus on Increased Energy Efficiency and Improved Comfort, Guidebook to IEA ECBCS Annex 37, Low Exergy Systems for Heating and Cooling of Buildings, VTT 2003

[13] Low Exergy Systems for High-Performance Buildings and Communities, report ECBCS Annex 49, Fraunhofer IBP 2011

[14] Schmidt, D.: Einsatz von innovativen LowExSystemen für Gebäude und Siedlungsgebiete, Presentation LowEx Symposium dt. Projektverbund des BMWi, 28. - 29. Oktober 2009

[15] Richter. S; Zepf, K.: Umstellung einer bestehenden Fernwärme in ein LowEx-System, Presentation Berliner Energietage 2010, 10.05. bis 12.05.2010 in Berlin

[16] Paulsen et al.: Consumer Unit for Low Energy District Heating Net, The 11th International Symposium on District Heating and Cooling, 31.8.-2.9.08, Reykjavik, ICELAND

[17] Wernstedt, F.; Johansson, c.: INTELLIGENT DISTRIBUTED LOAD CONTROL, The 11th International Symposium on District Heating and Cooling, August 31 to September 2, 2008, Reykjavik, ICELAND

[18] Zucker, G.; Hettfleisch, C.; Basciotti, D.; Judex, F.; Schmidt, R.R.: Energy Aware Building Automation Enables Smart Grid-friendly Buildings; e\&i Elektrotechnik und Informationstechnik, paper in print

[19] Prato, A.P.; Strobino, F.; Broccardo, M.; Giusino, L.P.: Integrated management of cogeneration plants and district heating networks, Applied Energy, Available online 13 March 2012, ISSN 0306-2619, 10.1016/j.apenergy.2012.02.038.

[20] Benonysson, A.; Bøhm, B.; Ravn, H.F.: Operational optimization in a district heating system, Energy Conversion and Management, Volume 36, Issue 5, May 1995, Pages 297-314, ISSN 0196-8904, 10.1016/0196-8904(95)98895-T.

[21] Andersson, S.: Influence of the net structure and operating strategy on the heat load of a district-heating network, Applied Energy, Volume 46, Issue 2, 1993, Pages 171-179, ISSN 0306-2619, 10.1016/0306-2619(93)90066-X.

[22] Basciotti, D.; Judex, F.; Pol, O.; Schmidt, R.R.: Sensible heat storage in district heating networks: a novel control strategy using the network as storage, IRES 2011, bcc Berlin Congress Center, 28.-30. November 2011 